\title{
La Ley de Ordenamiento Territorial y Desarrollo Sostenible. A 10 años del inicio del proceso de institucionalización del ordenamiento territorial
}

\author{
The Territorial Planning and Sustainable Development law. \\ 10 years after the beginning of the institutionalization process \\ of land use
}

\section{Carlos Castro Casas*}

\footnotetext{
* Doctor en Derecho y Ciencias Sociales, Universidad de la República (UdelaR), Uruguay. Maestría en Ordenamiento Territorial y Desarrollo Urbano (Facultad de Arquitectura, UdelaR). Profesor titular de Derecho Ambiental y Ordenamiento Territorial, Facultad de Derecho, Universidad CLAEH.

凶ccastroc@claeh.edu.uy
}

https://orcid.org/0000-00031341-8353

\section{Resumen}

Hace ya unos meses se cumplieron diez años de la promulgación de la ley 18.803, de 18 de junio de 2008, Ley de Ordenamiento Territorial y Desarrollo Sostenible. Su aparición en el orden jurídico uruguayo no ha sido indiferente. Estas líneas pretenden resaltar el hecho ubicándonos en el tema, contextualizar la aparición de la ley en el escenario nacional y comentar algunos de los aspectos que la han situado como una norma compleja y resistida.

Palabras clave: planificación regional, legislación, Uruguay.

\begin{abstract}
A few months ago, it was ten years since the enactment of Law 18.803 of June 18, 2008, Law of Land Management and Sustainable Development (LOTDS, by its acronym in Spanish). The appearance in the Uruguayan legal order has not been indifferent. These lines aim to highlight the event, placing us in the subject, contextualizing the appearance of the LOTDS in the national scenario, commenting on some of the aspects that have placed it as a complex and resisted law.
\end{abstract}

Keywords: regional planning, legislation, Uruguay. 


\section{Origen del ordenamiento territorial}

Aisladamente consideradas, las actividades que implica el ordenamiento del territorio se vienen haciendo desde hace mucho tiempo en el mundo, pero no ocurre lo mismo con el abordaje de su conjunto de manera integrada.

Según Hildebrand (1996, pp. 29-31), el concepto de ordenación del territorio se ha asociado a las políticas públicas del welfare state, que surgió en la mayoría de los países industrializados después de la Segunda guerra Mundial, aunque en algunos casos - como los de Alemania, Suiza y Holanda - se remonta a fechas anteriores. Al igual que otras políticas públicas, perseguía la mejora de las condiciones de bienestar y calidad de vida de los ciudadanos.

Es justamente en la posguerra cuando Louis-Joseph Lebret (citado por Mealla, 2016) propuso un nuevo enfoque del planeamiento urbano y territorial, basado en la Economía Humana, buscando «el desarrollo de todo el hombre y de todos los hombres». Este objetivo del desarrollo fue propuesto repetidamente por Lebret y asumido expresamente por Pablo VI (1967) en la encíclica Populorum Progressio: el desarrollo no se reduce al simple crecimiento económico; para ser auténtico debe ser integral, es decir, promover a todos los hombres y a todo el hombre. Se imponen un desarrollo integral y una economía al servicio del hombre. Precisamente, desarrollo integral era el concepto sobre el cual se asentaba toda la obra de Lebret (Mealla, 2016).

De acuerdo con la Carta Europea de Ordenación del Territorio, de 1983 —primer texto internacional que define la ordenación de territorio-, los objetivos fundamentales de esta son:

1. el desarrollo socioeconómico equilibrado de las regiones;

2. la mejora en la calidad de vida;

3. la gestión responsable de los recursos naturales y la protección del medio ambiente;

4. la utilización racional del territorio. ${ }^{1}$

Para Hildebrand, aun las posturas más liberales, que apostaban únicamente a la economía de mercado, identificaban al menos tres cuestiones de relevancia territorial para las que no encontraban solución, y que, por tanto, hacían necesaria la planificación: 1) las decisiones sobre localización de actividades de los agentes privados no conducían a una distribución geográfica equilibrada; 2) había bienes colectivos que requerían una gestión eficaz sin quedar sometidos a mecanismos de regulación de

1 Consejo de Europa. Aprobada el 20 de mayo de 1983 en Torremolinos (España). Conferencia Europea de Ministros Responsables de la Ordenación del Territorio. 
mercado, y 3) algunas decisiones de los agentes privados generaban efectos externos o costos sociales que se manifestaban en impactos negativos ambientales, económicos o sociales. Aun para las más acérrimas posiciones liberales, «la planificación territorial de los poderes públicos se convierte en un instrumento necesario que puede facilitar las soluciones adecuadas que la lógica del mercado no es capaz de aportar» (Hildebrand, 1996, p. 32).

El mismo autor expresaba que podían distinguirse dos concepciones de la ordenación del territorio: una «en el sentido de la planificación física a escala regional y subregional, con el objeto principal de la coordinación de los aspectos territoriales de las políticas sectoriales y la coordinación del planeamiento urbanístico municipal», y otra, más amplia o abarcadora, que «liga la ordenación del territorio estrechamente con la planificación económica y social y los objetivos de la política de desarrollo económico regional» (1996, p. 33).

También establecía una constante: las cuestiones vinculadas a la ordenación son más relevantes en las regiones más desarrolladas, debido a que en estas las cuestiones planteadas por el desarrollo ya se encuentran resueltas, en el sentido de que la dimensión de ordenación cobra más protagonismo cuanto mayor es el desarrollo de la región. Así, en los Länder alemanes, que pertenecen a las regiones más desarrolladas de la Unión Europea (UE), los planes se centran más en mejoras cualitativas que cuantitativas; en cambio, en algunas comunidades autónomas españolas consideradas menos desarrolladas (a los efectos de la distribución de los fondos estructurantes de la UE), la dimensión de desarrollo sigue estando en la primera línea de los planes (Hildebrand, 1996, p. 48).

\section{El ordenamiento territorial en Uruguay a partir de los noventa y la aprobación de la LOTDS}

En los últimos treinta años el orden jurídico uruguayo ha generado un proceso de descubrimiento del ordenamiento territorial.

El punto de partida puede situarse en la creación del Ministerio de Vivienda, Ordenamiento Territorial y Medio Ambiente (MVOTMA), en 1990, aunque en los años posteriores el sector Ordenamiento Territorial careció de gravitación a escala nacional.

Se ha dicho (Castro Casas, 2015) que la aprobación del Plan de Ordenamiento Territorial de Montevideo (conocido como POT), en 1998, ${ }^{2}$ elaborado por el Gobierno Departamental, fue un hito que trascendió el ámbito del departamento, por cuanto 
aplicó un nuevo modelo de consideración del territorio y de las acciones que en él se despliegan.

A partir de ahí, la toma de conciencia sobre la importancia de considerar integralmente el territorio en las políticas nacionales y departamentales se fue haciendo lugar en las agendas de los actores públicos. Se sucedieron varios intentos de legislar en la materia, hasta que en 2008 se aprobó la ley 18.308.

Desde ese momento, se pasó de una situación con múltiples normas dispersas que directa o indirectamente hacían ordenamiento territorial —aunque no se lo llamara así y su carácter asistemático conspirara con tal calificación - a tener una ley que proporciona normas de fondo sobre ordenamiento territorial y el derecho de propiedad sobre el suelo, a la vez que programa el despliegue de un variado menú de figuras normativas denominadas instrumentos. La ley propende a que dichas figuras contengan, en sus distintas escalas y alcances, los contenidos de la planificación y la gestión del territorio de un modo organizado y sistemático.

En términos generales, la LOTDS, vigente desde 2008, previó tanto cuestiones estructurantes del régimen como aspectos procedimentales y regulatorios de mayor detalle, cuya atención se ha tornado ineludible a la hora de operar sobre el suelo en el Uruguay.

Se institucionalizó el ordenamiento territorial introduciendo el modelo de la planificación como conducta jurídicamente vinculante, no solo para las unidades estatales competentes en la elaboración y la aprobación de las normas resultantes, sino también para todas aquellas otras cuya gestión se relacione con el uso del territorio, lo que hace que prácticamente todos los ámbitos estatales deban tener presente el tema en sus programaciones y acciones. A su vez, se incorporó el paradigma del desarrollo sostenible, en el sentido de propender a garantizar la solidaridad intergeneracional en el uso y el aprovechamiento de los recursos naturales y culturales.

Para entender el desarrollo del ordenamiento territorial en el Uruguay a fines del siglo XX y principios del XXI, no puede obviarse la fuente inspiradora de sus más trascendentes hitos normativos: el urbanismo español, que a pesar de su nombre es una disciplina que no solo abarca las conurbaciones, sino que ejerce su influencia en todo el territorio. ${ }^{3}$ Sobre él se ha dicho que tiene características únicas en el mundo, dado que ya en el período que Fernández (2011, p. 26) denomina paleourbanismo hispano, daba preponderancia a la acción privada en su desarrollo. Así, en relación con la Ley de Ensanche de 1864: 
Alternativamente a esta gestión pública y prácticamente de manera prevalente, la ley delegaba todo el proceso productivo en los propietarios de suelo que sumieran el protagonismo ejecutivo del mismo en régimen de monopolio, pero siempre bajo el control y dirección de la Administración [...].

De ahí que no sea desde la Ley de Suelo, de 1956, que los particulares asumen protagonismo en la urbanización española, sino desde mucho antes, lo que diferencia esta situación de otras realidades europeas.

Es de suponer que una ley que define su objeto como las acciones transversales del Estado «que tienen por finalidad mantener y mejorar la calidad de vida de la población, la integración social en el territorio y el uso y aprovechamiento ambientalmente sustentable y democrático de los recursos naturales y culturales» recoge aceptación unánime y apoyo en un moderno Estado social de derecho.

Sin embargo, ello no ha ocurrido con parte de sus contendidos, fundamentalmente los relacionados con el tratamiento del derecho de propiedad inmueble y los aspectos competenciales entre el Estado y los gobiernos departamentales, aspectos estos que plantean divergencias desde la etapa de tratamiento de la ley en el Parlamento.

La definición de от aporta un claro componente teleológico, identificado con un modelo de territorio en el que destaca su población, para la cual se propone mantener y mejorar la calidad de vida, asegurar la integración social y garantizarle el uso ambientalmente sustentable de sus recursos.

De este modo, desde la vigencia de la ley 18.308, las acciones del Estado programadas y ejecutadas como de ordenamiento territorial deben dirigirse hacia esa finalidad, y las que se aparten de ella devienen contrarias a derecho. No obstante, tratándose de expresiones de tal generalidad - y no podía ser de otra manera-, habrá en todo momento diferentes opiniones sobre si las acciones concretas se dirigen o no a dichas finalidades, ya que, por cierto, la complejidad en la tarea de gobernar hace que no haya un único camino para ello (Castro Casas, 2015).

\section{El modelo adoptado en Uruguay}

Es sabido que en el Uruguay existen marcadas asimetrías en términos de desarrollo por áreas de su territorio. No obstante, el modelo de OT adoptado es apto para abordar tanto el ordenamiento como el desarrollo, el cual necesariamente debe impulsarse en términos de sostenibilidad, en el sentido de equilibrar el crecimiento económico y el social de manera tal que no se comprometan las posibilidades para las generaciones futuras. 
Se ha sostenido que la aprobación de la Ley 18.308 del 18 de junio de 2008, debe destacarse como un acontecimiento fundamental en la historia de la legislación nacional. Puede haber distintas visiones sobre lo que es el territorio, pero sin duda se coincidirá en que hay muy pocas cosas relacionadas con el hombre que ocurran fuera de él. No se trata de una entidad estática; el territorio sobre el que operamos reconoce elaboraciones pretéritas y siempre está en medio de un ciclo de gestión. Se trata, pues, de un proceso que viene en marcha y que no se detiene, por lo que las decisiones actuales estarán condicionadas por las anteriores, que seguirán produciendo consecuencias aún en el modelo nuevo, lo que anticipa las dificultades de acometer su ordenación.

Asimismo, el proceso se da en el marco de una democracia, donde mayorías y minorías poseen gravitación, y las verdades técnicas, por más puras que vengan desde la disciplina asociada, requerirán la validación social y el acto político que las convierta en norma jurídica, lo que no siempre ocurre así, justamente por una de las fortalezas de la sociedad democrática, que contempla múltiples intereses y opiniones. Ello determina que los procesos encuentren obstáculos, se enlentezcan, y en ocasiones se vean obligados a sufrir ajustes que, si bien conspiran contra su integralidad, terminan siendo la única forma de validarlos ante el grupo.

En términos generales, la ley vigente desde 2008 institucionaliza la ordenación del territorio introduciendo el modelo de la planificación como conducta jurídicamente vinculante, no solo para las unidades estatales competentes en la elaboración y aprobación de las normativas resultantes, sino también para todas aquellas otras cuya gestión se relacione con el uso del territorio, lo que hace que prácticamente todos las ámbitos estatales deban tener presente el tema en sus programaciones y acciones. A su vez, incorpora el paradigma del desarrollo sostenible, en el sentido de garantizar la solidaridad intergeneracional en el uso y el aprovechamiento de los recursos naturales y culturales (Castro Casas, 2011).

La valoración sobre la LOTDS uruguaya incluyen apreciaciones muy diversas: que se trata de una ley plagada de inconstitucionalidades, que es una sumatoria de lineamientos y directrices sin fuerza de imposición alguna y, en el otro extremo, que se trata de una legislación de avanzada que ni Uruguay ni sus propios promotores estaban preparados para aplicar cuando se aprobó.

La consideración de si una ley viola o no la Constitución es - o debería ser- un tema de técnica jurídica ejercida de forma independiente y despojada de toda otra valoración que no sea la propia de dicha disciplina. Y ello rige tanto en el ámbito jurisdiccional como en el ámbito académico del derecho. Otras consideraciones, como las que provienen del discurso de inconstitucionalidad instalado culturalmente, ${ }^{4}$ deben 
quedar en el ámbito de la discusión política o, en todo caso, en la valoración de si la norma es buena o no.

En estas materias es natural que haya distintas visiones de los fenómenos, pues en ello está asentado el contrato social. En el plano del discurso, lo que para algunos puede ser una transgresión constitucional, para otros solamente constituye el resalte de ciertos derechos o garantías previstos en la norma y la moderación de ciertas facultades de otros. De alguna manera se trata de un juego legítimo en un campo donde no hay opiniones únicas ni certezas totales. De hecho, aun en el ámbito jurisdiccional, los cambios en la integración de los tribunales que resuelven causas de inconstitucionalidad - la Suprema Corte de Justicia en Uruguay - determinan en ocasiones cambios drásticos en la suerte de una ley (Castro Casas, 2015).

No cabe duda, sin embargo, de que se trata de una ley que afronta temas de nuestro tiempo y que pretende ir más allá de los contenidos imperativos típicos dados por las leyes tradicionales que se limitan a regular conductas. Aun así, mandata y promueve en las personas públicas la elaboración de los instrumentos de ordenamiento territorial (IOT), sentando reglas y procedimientos para ello; proporciona un marco legal para las acciones que se llevarán a cabo durante la gestión de los IOT; dispone cometidos a cargo de MVOTMA en actividades de contralor, coordinación y apoyo de los procesos, y vincula jurídicamente a los particulares con todo ello, estableciendo contenidos de la propiedad inmueble y enumerando sus deberes correlativos, con el propósito de hacer funcional el derecho de propiedad con los intereses colectivos que involucra el OT.

\section{Algunos aspectos que hacen a su complejidad}

Sin pretensión de agotarlos, se relevan brevemente algunos elementos propios de la disciplina y otros presentes en el modelo adoptado en Uruguay, que explican las dificultades que viene encontrando el proceso de institucionalización del oT.

\section{La complejidad del objeto sobre el que opera: el territorio}

El OT opera sobre el territorio, pero no según la concepción clásica estática que puede tener para una rama del derecho, como el derecho constitucional, para la cual se trata de un componente del Estado y un ámbito espacial de imputación de normas. El OT adopta una consideración dinámica de espacio físico, que integra los procesos sociales permanentes que se desarrollan en él. De esa forma, el ordenamiento territorial se involucra en la transformación de ese territorio, reconociéndolo como un fenómeno dinámico, que nunca se detiene. Por tanto, las intervenciones en esa entidad en permanente movimiento requieren un cuidado especial y no siempre dan los resultados 
esperados. En cierta medida, operar en el territorio es como hacerlo con el aire: se podrá regular lo que se quiera respecto de él, pero mientras tanto nadie podrá dejar de respirar.

Es muy gráfica la metáfora de André Corboz, quien presenta al territorio como un antiguo pergamino (palimpsesto) que se escribe y se borra sucesivamente. El territorio, sobrecargado de numerosas huellas y lecturas pasadas, se parece a un palimpsesto. Para colocar nuevos equipamientos o para explotar ciertas tierras de forma más racional, a menudo resulta indispensable modificar su sustancia de manera irreversible. Pero el territorio no es un embalaje perdido ni un producto de consumo que se pueda reemplazar. Cada territorio es único, de ahí la necesidad de reciclar, de raspar una vez más (pero con el mayor cuidado posible) el viejo texto que los hombres han inscrito sobre el irremplazable material de los suelos, a fin de depositar uno nuevo que responda a las necesidades de hoy, antes de ser a su vez revocado (Corboz, trad. 2004/1983).

De ese modo, las historias que se escriben sobre el territorio no se cambian fácilmente $y$, aunque se sobreescriban, dejan marcas perennes que condicionan el futuro.

\section{La amplitud de su materia}

En sus etapas previas, cuando en el ámbito académico y político se debatía sobre el alcance y los contenidos de la ley, definir una materia propia era uno de los problemas determinantes. No estaban claros sus límites y, dado que se trataba de una ley acerca del ordenamiento del territorio, fuera del cual pocas cosas ocurren, existía el riesgo de abarcar aspectos que invadirían otras áreas de actividad. La ley finalmente aprobada adoptó el concepto amplio de OT mencionado por Hildebrand (1996, p. 33) y en su artículo 4 elaboró un vasto listado de la materia que comprende el ordenamiento territorial. La lectura atenta de la ley también permite encontrar, en otros pasajes, actividades que deben considerarse comprendidas como materia de от (como los contenidos preceptivos de los IOT, entre otros).

\section{Acciones transversales, coordinadas e integradas}

Una de las principales apuestas de la LOTDS es quebrar el paradigma de la actuación territorial desintegrada y aislada de las personas públicas, privilegiando las acciones coordinadas y articuladas basadas en el intercambio de información. Ello se traduce en inducir a todas las esferas estatales para que piensen y actúen en clave territorial, según el principio de la coordinación y la cooperación, sin perder sus pro- 
pias identidades, además del fomentar la coordinación entre el sector público, el privado y el social (artículo 5 , literal $b$, de la LOTDS).

Para la aprobación de los primeros IOT de los previstos en la LOTDS se requirió la capacitación de recursos humanos y la voluntad política de los gobiernos departamentales, lo cual supuso que el MvoTMA desplegara apoyos a los gobiernos departamentales a través de su Dirección Nacional de Ordenamiento Territorial (DINOT) y diversos programas gubernamentales. La apuesta fue intentar mapear el territorio nacional con la categorización prevista en la LOTDS, como forma de crear las condiciones aptas para recibir la implantación de usos del suelo en una lógica de desarrollo sostenible. De ese modo, hubo apoyo técnico, económico y capacitación destinados a los gobiernos departamentales.

En este proceso de aplicación de la ley hubo una primera generación de problemáticas, asociadas a la creación y aprobación de los instrumentos de ordenamiento territorial por los gobiernos departamentales, fundamentalmente directrices departamentales y planes locales. Luego, una vez que aquellas se superaron, se presentó la necesidad de resolver una segunda generación de problemáticas, ahora vinculadas a la puesta en práctica real de los contenidos de esos instrumentos de planificación, la cual se encuentra en pleno proceso de superación.

\section{La incursión en instituciones seculares del derecho y el establecimiento de nuevas figuras que las condicionan}

La LOTDS, además de proponer un cambio de paradigma en la consideración del territorio y mandatar a las autoridades competentes para la elaboración y gestión de los IOT, ha incursionado en regulaciones de fondo acerca de diversas temáticas que desde hace mucho tiempo vienen siendo abordadas por distintas ramas del derecho y que van más allá del ordenamiento territorial.

Así, lo atinente al derecho de propiedad inmobiliaria, con la formulación de contenidos del derecho y deberes asociados, es un aspecto muy novedoso en nuestra legislación (artículos 35 y 37). Si bien no hay menciones expresas en la ley, va de suyo que esta deroga tácitamente algunos preceptos contenidos en el Código Civil (artículos 486 y siguientes), por directa contradicción conceptual. Lo mismo ocurre con la prescripción adquisitiva abreviada por razones de interés social, que introduce su artículo 65 , en particular en su versión colectiva, por el grado de incertidumbre jurídica que puede llegar a generar. La regulación del derecho de superficie como derecho real, sin una compaginación con otros derechos reales menores (como el de usufructo), plantea confusiones sobre su régimen y dudas sobre su utilidad. 


\section{La necesidad de equilibrios jurídicos en la formulación y gestión de los planes}

El ordenamiento territorial se expresa a través de sus instrumentos, los cuales requieren validación a través del acto jurídico correspondiente.

Se ha dicho que Uruguay no escapa a la necesidad de superar el divorcio entre el jurista y los técnicos que contribuyen a ordenar el territorio a partir del diseño y el proyecto. El primero está imbuido, por formación, de la rigidez decimonónica del estatuto de la propiedad, que caracteriza los códigos civiles latinoamericanos dictados bajo la influencia del Código Napoleón; los segundos operan en el territorio con cierto menosprecio por los esquemas dominiales seculares, sin tener en cuenta los valores instrumentales de certeza y seguridad jurídica que mantienen vigencia al día de hoy y que son de indiscutible utilidad social hasta tanto sean sustituidos por otros mejores (Castro Casas, 2015).

Los productos del OT tienen necesariamente un origen técnico-disciplinar, pero luego deben ser canalizados por las instancias político-institucionales correspondientes.

A menudo se constata que la formación del planificador le determina una naturaleza universalista e integradora de todos los fenómenos, con límites difusos. Los juristas, en cambio, son en esencia clasificadores y permanentes generadores de categorías: separan, generan compartimentos estancos, tienen claro lo que está dentro y lo que está fuera, lo que es, lo que no es y lo que debe ser.

De ahí que la actividad del planificador, con su componente de incertidumbre, saque al jurista de su zona de confort y por momentos interpele su utilidad, como si fuera meramente un creador de infraestructuras artificiosas de control social.

La práctica del ordenamiento territorial, en estos diez años transcurridos desde la aprobación de la ley, ha permitido ir superando estas problemáticas. Así, cada vez más se ve a los operadores del derecho integrados a los equipos interdisciplinarios elaborando productos de от. El mutuo recelo entre las disciplinas asociadas a lo proyectual aplicadas al territorio y el derecho va quedando de lado en tanto se logra una mejor complementariedad.

Sin embargo, no ha ocurrido — al menos hasta ahora- que el ordenamiento territorial genere el efecto que tuvo el urbanismo en la creación de una rama del derecho especializada, que en su caso fue el derecho urbanístico. En sociedades como la española, esta rama del derecho ha tenido un gran desarrollo y ha cobijado al ordenamiento territorial, que es estudiado junto con el urbanismo como un fenómeno único.

Lo cierto es que quienes pretendan abordar la disciplina del OT desde una perspectiva jurídica deben despojarse por momentos de sus especialidades de iuspublicistas y de iusprivatistas, pues serán convocados a sumergirse en conocimientos de cada 
una de dichas ramas y deberán acostumbrarse a una dinámica de permanentes combinaciones y entrecruzamientos entre institutos y conceptos que, si bien son elaborados con enfoques distintos, deben lograr armonía o al menos llegar a un nivel de conflicto superable ante su objeto de estudio.

Con base en estas ideas, en noviembre de 2013, cuando habían transcurrido cinco años de la aprobación de la LOTDS, la Facultad de Derecho del CLAEH organizó cabo un ciclo de conferencias sobre ordenamiento territorial que convocó a especialistas de diversas ramas del derecho. ${ }^{5}$ Se destacaba la oportunidad de operar conocimiento de ordenamiento territorial desde la disciplina jurídica, considerando que sus temáticas son abordadas principalmente desde los ámbitos técnicos y muchas veces la aparición de los juristas es tardía, lo que lleva a que los productos que se generen no tengan la precisión ni la eficiencia adecuadas.

\section{La resistencia a su aplicación}

La ley ha tenido desde el comienzo críticos de diversa índole. Ya desde la discusión parlamentaria se plantearon discrepancias con algunos de sus postulados y disposiciones en particular. Durante su tratamiento en la comisión del Senado, varios de los invitados calificados se pronunciaron en contra. Luego de aprobada, algunos juristas sostuvieron que buena parte de sus contenidos eran inconstitucionales (Martins, 2009), mientras que otros se adentraron en sus temáticas abordando sus postulados con enfoque de sistema (Gorosito y Ligrone, 2009).

Pero, además de las críticas directas, en los propios ámbitos contemplados en la ley se han encontrado dificultades para su aplicación. En muchos sectores de la Administración cuyos asuntos se desarrollan con una gran vinculación al territorio se actúa con independencia del nuevo modelo. Sigue siendo difícil introducir la actuación en clave territorial en diversos sectores de actividad pública en los cuales, si bien los cometidos de ordenamiento territorial están ausentes, sus acciones propias tienen gran incidencia territorial, al extremo de hacer imposible ordenar el territorio sin su participación (actividad forestal, minera, grandes infraestructuras, etcétera).

Los gobiernos departamentales, en su mayoría recelosos de la LOTDS en un principio, fueron descubriendo las oportunidades que la ley les proporcionaba en términos de aumentar su gravitación en sus respectivos territorios, por lo que se convirtieron, junto con el MVOTMA, en los principales desarrolladores del nuevo modelo. No podía ser de otra manera, por cuanto la ley les atribuye competencias específicas exclusivas con

5 Se recordó en la oportunidad al Dr. Patricio Rodé como precursor en nuestro medio de las reflexiones jurídico-territoriales, con énfasis en los aspectos sociales que de ellas derivan: «Estas temáticas fueron siempre sus desvelos, sus reflexiones se refirieron a las problemáticas del suelo y sus conexiones con el Derecho con especial preocupación por la situación de los más vulnerables» (CLAEH, 2015). 
relación a su suelo y confiere materia específica a sus reclamadas autonomías (casos de sus artículos 14 y 30, entre otros).

\section{Los conflictos competenciales}

Hay una distinción que se ha venido dando desde hace tiempo, aunque con distintos nombres, entre lo que podrían ser las competencias directas en materia de ordenamiento territorial, destinadas a ciertos órganos nominados a esos efectos, y otras que, sin pretender tener por objeto el ordenar el territorio, generan condicionamientos o alteraciones a las decisiones que sí son propias de OT. La LOTDS, en su artículo 1, expresa que establece el marco regulador del ordenamiento territorial y desarrollo sostenible sin perjuicio de las demás normas aplicables y de las regulaciones que dispongan el Poder Ejecutivo y los gobiernos departamentales, reconociendo que existe otra legislación que impacta el от.

En España, la Constitución habilita a las comunidades autónomas a asumir competencias legislativas sobre «ordenación del territorio, urbanismo y vivienda». Luego, los estatutos de autonomía atribuyeron a sus respectivas comunidades la competencia exclusiva sobre tales materias. A su vez, existen «competencias del Estado en materias próximas y conexas», ya que, si bien se acepta en principio que el Estado carece de competencia en materia de urbanismo, ordenación del territorio y vivienda, la posee en otras materias distintas que, sin embargo, «le permite[n] aprobar algunas normas que afectan al urbanismo y que, además, se imponen a los legisladores autonómicos de manera que estos, al dictar sus leyes urbanísticas y de ordenación del territorio, tienen que respetar esa legislación estatal» (Rebollo, 2007, p. 45).

Aceptado esto, el tema se centra en delimitar el alcance de esas competencias cruzadas sobre materias conexas con el urbanismo. De ese modo, se concluye que la exclusiva competencia autonómica en materia de urbanismo y ordenación del territorio, «hace que la legislación estatal tenga que proceder con cautela sin hacer propia y directamente determinaciones urbanísticas ni condicionar, más allá de lo imprescindible desde el punto de vista de sus competencias no urbanísticas, la legislación autonómica» (Rebollo, 2007, p. 54).

Volviendo a Uruguay, la generación de estos actos con incidencia territorial es una consecuencia de la cual pocas unidades de la Administración pública pueden escapar, por cuanto la operativa estatal, al igual que la mayoría de las acciones de las personas físicas y jurídicas, se desarrolla en el territorio. En general, quienes ejercen estas competencias con injerencia territorial deberían adaptarse en las determinaciones dadas por los ámbitos competenciales directos, es decir, por quienes ejercen competencias deliberadas de OT, por razones no de jerarquía sino de especialidad. No obstante, se reconocen temáticas extremas, tales como la seguridad nacional, el orden inter- 
no, emergencias sanitarias o las originadas por fenómenos naturales, entre otras, que escapan a esa prelación. En el mismo nivel se ubican aquellas relativas a la protección del ambiente (artículo 47 de la Constitución de la República Oriental del Uruguay, leyes 16.466, de 14 de enero de 1994, y 17.283, de 28 de noviembre de 2000, principalmente).

En otros casos, fundados en resolver temáticas que no presentan tal gravedad, donde las razones son de oportunidad o conveniencia, debería darse la elaboración concertada a los efectos de evitar conflictos y contradicciones entre los ámbitos competenciales concurrentes. El proceso de elaboración de los IOT habilita, en las instancias de comunicación y solicitud de información sobre las incidencias territoriales en el ámbito del instrumento en elaboración, la detección —no siempre tan temprana como debería ser- de los posibles conflictos o contradicciones que puedan presentarse, originados en el ejercicio de competencias concurrentes o sobrepuestas de diferentes personas públicas, a los efectos de articular soluciones en forma previa a su aprobación definitiva. También el Comité Nacional de Ordenamiento Territorial (CONAOT) puede ser un ámbito apropiado para saldar las discusiones (Castro, 2018).

\section{Las tensiones generadas con las facultades del derecho de propiedad}

Se ha dicho que para el fluido desenvolvimiento de las políticas y prácticas de ordenamiento territorial es de importancia encontrar el vital equilibrio entre las libertades individuales y el ejercicio de las funciones públicas implicadas (Castro, 2015). Un buen comienzo puede ser el reconocer las dificultades que ello trae aparejadas.

Desde siempre ha existido una relación crítica entre el estatuto del derecho de propiedad y el ordenamiento territorial. El conflicto aparece desde la fase de diseño de las políticas y se mantiene en la elaboración normativa y luego en la gestión. Esta situación se observa desde hace tiempo y no solamente en la ordenación del territorio; también aparece en el juego de otras actividades públicas vinculadas al bienestar general, que entran en conflicto con los derechos individuales. Lo vemos en el tema ambiental, patrimonial, cultural, en la organización del espacio público-privado en las ciudades, etcétera.

El punto es muy sencillo: existe un conflicto esencial entre el interés individual y el interés de la colectividad. Es una relación de tensión, que se controla pero no se resuelve, porque es consustancial a todo grupo social. Desde que hay dos personas interactuando es posible distinguir el interés individual del colectivo. Lo vivimos a diario en nuestras actividades habituales. El conflicto, llevado al teatro de la sociedad y refiriéndolo al suelo como espacio inevitable para el desarrollo de la vida, cobra magnitud. A ello se agregan los factores económicos y de poder que lo relacionan con 
organizaciones, teorías y creencias, así como con el bienestar de las personas, con lo que cobra una dimensión de esencialidad en la vida de cualquier sociedad.

Todo gobernante — sea nacional, departamental o local- toma permanentemente decisiones vinculadas a estas problemáticas en que la tensión se encuentra presente.

Desde finales del siglo XVIII, la impregnación de las ideas del liberalismo en el campo del derecho ha determinado la presencia del derecho de propiedad en los repertorios jurídicos, aunque por mucho tiempo solo identificado como un estatuto de situaciones activas, que concedían poderes al propietario y lo protegían de intromisiones foráneas. Luego, en su evolución, se ha visto modalizado en sus contenidos y facultades, y se le ha agregado una serie de contrapartidas a cargo del propietario para situarlo en una condición de poder-deber, como se lo concibe en nuestros tiempos.

Hace años que, en los países que han desarrollado primero el urbanismo y luego el ordenamiento territorial, la relación entre quienes postulan los aspectos individualistas del derecho de propiedad y la institucionalidad que aplican el uno y el otro vienen teniendo continuos desencuentros.

Es que tanto el ejercicio de los derechos subjetivos como las acciones o restricciones del urbanismo y el ordenamiento territorial se explayan sobre el mismo campo de acción, con visiones e intereses que en ocasiones se presentan contrapuestos. De alguna manera es el eterno conflicto entre los intereses de la comunidad, representada por el Estado o el gobierno regional o local, y los particulares en el ejercicio de sus derechos subjetivos, principalmente el derecho de propiedad.

Actualmente, cuando han transcurrido más de diez años de aprobada la LOTDS, se mantienen los mismos esquemas de apropiación de suelo —aunque modalizados en algunos aspectos - y ello no ha obstado a que la institucionalización de la ordenación del territorio esté en marcha. Por otra parte, en todo este tiempo no ha habido declaraciones de inconstitucionalidad de la ley 18.308 basadas en afectaciones al derecho de propiedad, a pesar de todos los anuncios efectuados durante su proceso de elaboración y después de aprobada. ${ }^{6}$

Puede decirse que la nueva presentación del derecho de propiedad reclamada desde el ordenamiento territorial, si bien parte de fundamentos distintos, en lo exterior y en cuanto a la posición de su titular no presenta más que un moldeado de sus facultades, que también se da en otras materias, pero acá genera más reacciones por-

Por el contrario, existen pronunciamientos de la Suprema Corte de Justicia que rechazan demandas basadas en supuestas inconstitucionalidades provenientes del régimen de prescripción adquisitiva abreviada por razones de interés social previsto en su artículo 65 (sentencias de la Suprema Corte de Justicia [SCJ] 82/2010, 502/2013 y 137/2014) y del régimen de policía territorial instaurado por sus artículos 68 y 69 (sentencia SCJ 40/2013 LJU UY/JUR/84/2013). También actos administrativos basados en la aplicación de la LOTDS, procesados en el contencioso anulatorio, que han salido airosos de este (sentencia 75/214 del Tribunal de lo Contencioso Administrativo [TCA] publicada en CADE módulo jurídico). 
que el suelo es el objeto donde las facultades del derecho de propiedad tienen su mayor expresión. Recordemos que el derecho de propiedad nace en relación con los bienes muebles, pero no por acción deliberada, sino porque la efectividad del dominio sobre la tierra era muy difícil o imposible de controlar. Cuando ello se logra, pasa a ser el objeto principal, el más valioso, el que más poderes otorga. Antes era del soberano, luego del señor feudal y ahora del propietario.

La sociedad actual reclama cada vez más como estrategia de supervivencia —en todas las materias - la jerarquización del interés colectivo sobre el individual del propietario.

Otras sociedades se han visto en la emergencia de privilegiar la consideración del suelo en el interés colectivo, como es el caso de los Países Bajos, donde la propiedad privada ha estado siempre subordinada al interés general. Allí el suelo es privado, pero su uso debe acomodarse al interés público. Ello es así por cuanto desde la baja Edad Media el suelo fértil o pólder viene siendo ganado al mar con el esfuerzo de todos, lo que lleva a que el uso público con finalidades de ordenación no suscite rechazos ni ansias especuladoras en los propietarios (Castro, 2015).

\section{Resumen final}

A pesar de todas las dificultades apuntadas, transcurridos diez años de la aprobación de la LOTDS, la institucionalización del ordenamiento territorial es un hecho en el Uruguay; lo prueban los múltiples instrumentos de ordenamiento territorial que se han aprobado y que se vienen ejecutando.

Como toda ley compleja, ha tenido que sufrir ajustes, y sin duda tendrá otros en el futuro. Aún tiene mucho para dar, y su pleno desarrollo llegará cuando todas las unidades estatales asuman la actuación en clave territorial, lo que no implica ceder competencias ni perder terreno en sus ámbitos de actuación, sino solo poner en funcionamiento los postulados que hacen a la transversalidad de las acciones, conjugando las coordinaciones, colaboraciones e intercambios de información que habiliten una práctica eficiente.

Tal vez sea una ley que se ha adelantado a su tiempo, sin considerar los espacios de amortiguación que requiere el Uruguay para procesar los cambios en sus paradigmas. El paso del tiempo va remediando esto, en el sentido de que las personas públicas van incorporando en sus agendas la dimensión territorial y, por extensión, esta ya está siendo considerada por los agentes privados.

Los gobiernos departamentales, a su vez, se han involucrado en sus temáticas, viendo en su desarrollo una herramienta para el afianzamiento de sus competencias 
en el suelo departamental y una oportunidad para el crecimiento ordenado en términos de sostenibilidad.

Hace poco más de un año se aprobaron por ley las Directrices Nacionales de Ordenamiento Territorial y Desarrollo Sostenible (ley 19.525, de 2017). Se trata del instrumento general de la política pública en materia territorial y, por tanto, una pieza clave en el andamiaje del sistema de la LOTDS, que incorpora una mirada comprensiva de todos los aspectos que juegan en las políticas territoriales del país. Si bien la aprobación de las Directrices Nacionales no reunió los consensos deseados, se espera que en su gestión puedan superarse las diferencias para no desaprovechar esta oportunidad que ofrece el instrumento, el cual trae el recuerdo de la visión planificadora y los postulados integradores de la CIDE de principios de los años sesenta.

\section{Bibliografía}

CASTRO CASAS, C. (2011). «Introducción al marco legal del ordenamiento territorial». En Ordenamiento territorial: Programa de formación y capacitación para implementar procesos de ordenamiento territorial (Proyecto Forte, Uruguay Integra). Montevideo: s.n.

CAStro CASAS, C. (2015). Principales aspectos jurídicos de los Programas de Actuación Integrada previstos en la Ley de Ordenamiento Territorial y Desarrollo Sostenible, en sus vinculaciones con el derecho de propiedad. (Tesis de Maestría). Facultad de Arquitectura, Montevideo. Recuperado de https://www.colibri.udelar. edu.uy/jspui/bitstream/123456789/8069/1/CAS127.pdf.

CAStro CASAS, C. (2018). Reflexiones sobre materia y competencia de ordenamiento territorial. Un aporte para clarificar los aspectos relacionados con el ejercicio de cometidos de ordenamiento territorial en sus diferentes niveles. Montevideo: Facultad de Arquitectura, Diseño y Urbanismo.

CLAEH (2015). Ciclo de conferencias sobre ordenamiento territorial. Recuperado de http://www.claeh.edu.uy/derecho/es/noticias/novedades/item/413-ciclo-deconferencias-sobre-ordenamiento-territorial.html.

CONSEjo DE EuRopa (1983). Carta europea de ordenación del territorio. Recuperado de https://alojamientos.uva.es/guia_docente/uploads/2013/474/46059/1/Docum ento37.pdf

Constitución de la República Oriental Del Uruguay (1967). Asamblea General, Montevideo, Uruguay, 24 de agosto de 1966.

Corboz, A. (2004). «El territorio como palimpsesto». En A. M. RAmos (coord.), Lo urbano en 20 autores contemporáneos (pp. 25-34). Barcelona: UPC.

FERNÁNDEZ, G. R. (2011). Para comprender el urbanismo español. Madrid: IUSTEL. 
Gorosito, R. \& Ligrone, P. (2009). Regímenes jurídicos actualizados: Sistema de ordenamiento territorial y desarrollo sostenible: Ley fundante 18.308. Montevideo: La Ley Uruguay.

Hildebrand, A. (1996). Política de ordenación del territorio en Europa. Sevilla: Universidad de Sevilla.

Junta Departamental De Montevideo (1998). Decreto 28.242. Recuperado de http://normativa.montevideo.gub.uy/content/dtojdm-28242-de-16091998.

LEY 16.466 (1994). Medio ambiente: Declárase de interés general, la protección del mismo contra cualquier tipo de depredación, destrucción o contaminación. Recuperado de https://parlamento.gub.uy/documentosyleyes/leyes/ley/16466? width $=800 \&$ height $=600 \&$ hl=en_US1\&iframe=true\&rel=nofollow.

LEY 17.283 (2000). Declárase de interés general, de conformidad con lo establecido en el artículo 47 de la Constitución de la República, que refiere a la protección del medio ambiente. Recuperado de https://parlamento.gub.uy/documentosyleyes/ leyes $/$ ley $/ 17283$ ?width=800\&height $=600 \& \mathrm{hl}=$ en_US1\&iframe=true\&rel=nofollow .

LEY 18.308 (2008). Ordenamiento territorial y desarrollo sostenible. Recuperado de https://parlamento.gub.uy/documentosyleyes/leyes/ley/18308?width=800\&he ight $=600 \&$ hl=en_US1\&iframe=true\&rel=nofollow .

LEY 19.525 (2017). Directrices nacionales de ordenamiento territorial y desarrollo sostenible. Recuperado de https://parlamento.gub.uy/documentosyleyes/leyes/ ley/19525?width=800\&height=600\&hl=en_US1\&iframe=true\&rel=nofollow .

MARTINS, D. (2009). Ordenamiento territorial: Análisis de la ley 18.308. Montevideo, FCU.

MeAlla, E. (2016). «L. J. Lebret: pionero de otro desarrollo». Revista Criterio, 2425. Recuperado de https://www.revistacriterio.com.ar/bloginst_new/2016/05/31/l-j-lebretpionero-de-otro-desarrollo/.

PAPA PABlo VI (1967). Populorum progressio. [Carta encíclica]. Recuperado de http://w2.vatican.va/content/paul-vi/es/encyclicals/documents/hf_p-vi_enc_ 26031967_populorum.html.

Rebollo, M. (coord.). (2007). Derecho urbanístico y ordenación del territorio en Andalucía. Madrid: IUSTEL.

URuguay. Suprema Corte DE JuSTiCiA. Sentencia 82/2010 (26/047/2010). Van Rompaey Servillo, L. A. (redactor), Chediak González, J. O., Van Rompaey Servillo, L. A., Gutiérrez Proto, D. I., Rubial Pino, J., Larrieux Rodríguez, J. T. Chao Fernández, M. B. (firmantes).

Uruguay. Suprema Corte de Justicia. Sentencia 40/2013 (06/03/2013). Pérez Manrique, R. C. (redactor), Tovagliare Romero, F. R., Chediak González, J. O., Chalar 
Vecchio, J. C., Larrieux Rodríguez, J. T., Pérez Manrique, R. C., Ruibal Pino, J. (firmantes).

Uruguay. Suprema Corte de Justicia. Sentencia 502/2013 (30/10/2013). Chediak González, J. O. (redactor), Tovagliare Romero, F. R., Chediak González, J. O., Chalar Vecchio, J. C., Larrieux Rodríguez, J. T., Pérez Manrique, R. C., Ruibal Pino, J. (firmantes).

Uruguay. Suprema Corte de Justicia. Sentencia 137/2014 (24/03/2014). Pérez Manrique, R. C. (redactor), Tovagliare Romero, F. R., Chediak González, J. O., Chalar Vecchio, J. C., Larrieux Rodríguez, J. T., Pérez Manrique, R. C., Ruibal Pino, J. (firmantes), Chalar Vechio, J. C. (discordante).

Uruguay. Tribunal de lo Contencioso Administrativo. Sentencia 75/014 (06/03/2014). Dr. Tobía, Dr. Preza, Dr. Harriague (redactor), Dra. Sassón, Dr. Gómez Tedeschi. 